\title{
ESTUDO DA APLICAÇÃO DA LÓGICA NEBULOSA NA OTIMIZAÇÃO DA LOGÍSTICA DE MATERIAL EM UMA EMPRESA DO SETOR ELÉTRICO BRASILEIRO
}

\author{
Rodrigo Costa dos Santos \\ Eletrobras S/A | COPPE/UFRJ \\ Av. Pres. Vargas, $409-12^{\circ}$ andar Centro \\ Rio de Janeiro - RJ - CEP: 20.071-003 \\ rodrigo@eletrobras.com \\ Francisco Eugênio de Aguiar Cavalcante \\ Eletrobras S/A | CEFET-RJ \\ Av. Pres. Vargas, $409-12^{\circ}$ andar Centro \\ Rio de Janeiro - RJ - CEP: 20.071-003 \\ francisco.cavalcante@eletrobras.com
}

\begin{abstract}
RESUMO
O presente artigo visa apresentar o estudo para a definição de critérios para a readequação da estrutura de logística de material de um Centro de Serviços Compartilhados (CSC) de um grupo empresarial do setor elétrico brasileiro, a partir de ferramentas de sistema de inferência fuzzy, considerando as especificidades dos almoxarifados de material. A aplicação dos critérios técnicos definidos pelo estudo subsidiará a otimização dos recursos e ganhos de sinergia, assegurando a disponibilidade de material, em tempo, custo e condições técnicas adequadas à manutenção da confiabilidade do sistema elétrico, dentro de padrões requeridos pela Companhia.
\end{abstract}

Palavra-chave: logística; readequação almoxarifado; centro de serviços compartilhados; lógica fuzzy.

\begin{abstract}
This paper aims to present the study for the definition of criteria for the material logistics structure readjustment of a Shared Services Center (CSC) of a business group of the Brazilian electric sector, using fuzzy inference system tools, considering the specifics of the warehouses of material. The application of the technical criteria defined by the study will support the optimization of resources and synergy gains, ensuring the availability of material, in time, cost and appropriate technical conditions to maintain the reliability of the electrical system, within standards required by the Company.
\end{abstract}

Keywords: logistics; warehouse readjustment; shared service center; fuzzy logic.

\section{Como Citar:}

SANTOS, Rodrigo Costa dos; CAVALCANTE, Francisco Eugênio de Aguiar. Estudo da aplicação da lógica nebulosa na otimização da logística de material em uma empresa do setor elétrico brasileiro. In: SIMPÓSIO DE PESQUISA OPERACIONAL E LOGÍSTICA DA 
MARINHA, 19., 2019, Rio de Janeiro, RJ. Anais [...]. Rio de Janeiro: Centro de Análises de Sistemas Navais, 2019

\section{INTRODUÇÃO}

A Eletrobras é uma empresa de economia mista de capital aberto, controlada pelo governo federal, que detém $51 \%$ das ações ordinárias. Sob o controle da Eletrobras estão as seguintes empresas de geração e transmissão de energia elétrica: Eletrobras Amazonas GT, Eletrobras CGTEE, Eletrobras Chesf, Eletrobras Eletronorte, Eletrobras Eletronuclear, Eletrobras Eletrosul e Eletrobras Furnas, com uma capacidade instalada de produção de 48.134 MW (31\% do total nacional), distribuída em 48 usinas hidrelétricas, 112 termelétricas, 70 eólicas e duas nucleares, e uma malha de linhas de transmissão, única no mundo, de abrangência nacional, com 64.944 km de linhas de transmissão em alta e extra-alta tensão, 49\% do país [1].

Com vistas ao realinhamento estratégico voltado à eficiência operacional, expansão sustentável e novo modelo de governança e gestão, a Eletrobras tem adotado nos últimos anos uma série de iniciativas, das quais se destaca a implantação de um Centro de Serviços Compartilhados (CSC) abrangendo oito processos: Recursos Humanos, Tecnologia da Informação, Contabilidade, Finanças, Jurídico, Serviços Gerais, Suprimentos e Logística.

A partir da nova estrutura organizacional, a Coordenação de Logística da CSC passou a administrar uma das maiores estruturas de logística de materiais sobressalentes e consumíveis de apoio do Setor Elétrico Brasileiro, composta por diversos almoxarifados associados aos empreendimentos das empresas do grupo.

O presente artigo visa apresentar o estudo para a definição de critérios para a readequação da estrutura de logística de material das empresas Eletrobras, a partir de ferramentas de sistema de inferência fuzzy, ou lógica nebulosa, considerando as especificidades dos almoxarifados de material MRO (manutenção, reparo e operação) das empresas Eletrobras, a saber: grande número de SKUs, baixíssimo giro, alta obsolescência e necessidade da proximidade dos almoxarifados com os locais de aplicação.

\section{REVISÃO DA LITERATURA}

\subsection{LogísticA}

Segundo Council of Logistics Management [2], logística é o processo de planejar, implementar, e controlar de maneira eficiente o fluxo e a armazenagem de produtos, bem como os serviços e informações associados, cobrindo desde o ponto de origem até o ponto de consumo, com o objetivo de atender aos requisitos do consumidor.

A logística observa de que forma a administração pode tornar melhor a rentabilidade dos trabalhos de disposição aos consumidores, procurando tornar disponíveis os produtos, em boas condições de uso, com custo inferior e retorno superior, sobre possíveis investimentos.

Entre os processos logísticos, é possível destacar as questões relacionadas à gestão dos pedidos, dos sistemas de transporte e os mecanismos de armazenagem Dentre estes, os processos de armazenagem são fundamentais para oferecer a disponibilidade de recursos frente às demandas de uma organização, pois um bom controle do armazém permite o rápido resgate de materiais e a gestão eficiente dos recursos. 
Em [11], os autores citam várias vantagens de se armazenar, dentre as quais ressalta a vantagem econômica, que segundo eles não são difíceis de quantificar, bastando apenas uma análise de trade-off entre os custos logísticos. Outra vantagem apresentada pelos autores supracitados é a de serviço que não está diretamente relacionado com a redução de custos, mas sim estão associadas ao tempo e localização. Bowersox e Closs [11] compreendem que o estoque não só é uma variável bastante significativa como também essencial, onde um mau gerenciamento poderia ocasionar fortes gastos, tendo em vista que o estoque corresponde à parte da organização que possui maior valor de capital retido.

Entre outras finalidades e vantagens citadas, em [12], o autor diz existir quatro pontos necessários para uma armazenagem eficaz: a obtenção de economias de transporte, redução dos custos de produção na produção por permitir um fluxo constante no suprimento de materiais para a produção de bens e serviços, principalmente considerando o tempo existente entre a produção, o consumo e as flutuações do mercado, em terceiro facilitar um pronto atendimento às exigências dos clientes, e por último permitir a obtenção de descontos nas compras de grandes quantidades.

Segundo [4], cada vez mais as empresas procuram alternativas para facilitar o gerenciamento de suas atividades, visando aumentar o controle e obter informações precisas que possam de fato agilizar a tomada de decisões e, consequentemente, melhorar o nível de serviço prestado. A atividade de armazenagem também vem ganhando, cada vez mais, importância dentro da cadeia de suprimentos. É através do gerenciamento da armazenagem, de forma eficiente e eficaz, que se torna possível melhorar a integração com os demais processos da organização, reduzir custos e otimizar o atendimento ao cliente.

Para [3], a rede de armazenagem de uma empresa influencia decisivamente no nível de serviço da disponibilidade de tempo em que o pedido será entregue. Segundo o autor, as principais características do nível de serviço estão relacionadas ao preço e ao serviço, tornando-se importante, pois através dele é que conseguimos medir a qualidade do serviço, o tempo de entrega, a quantidade e qualidade dos produtos entregues desde o inicio até o final do ciclo.

Desse modo, segundo [3], um bom planejamento da logística deve ser executado para que o nível de serviço seja eficiente e tenha uma grande eficácia em todo o processo, principalmente em caso imprevisto para que não tenha grandes prejuízos para os clientes.

De acordo com [2], pode-se apontar como metas da logística moderna prazos previamente acertados e cumpridos integralmente ao longo de toda a cadeia de suprimentos; integração efetiva e sistêmica entre todos os setores da empresa; integração efetiva e estreita (parcerias) com fornecedores e clientes; busca da otimização global, envolvendo a racionalização dos processos e redução de custos em toda a cadeia de suprimentos e satisfação plena do cliente, mantendo nível de serviço preestabelecido e adequado.

\subsection{Centro de Serviços Compartilhados}

A competitividade é um dos grandes temas em pauta quando se trata do sucesso no ambiente empresarial. As grandes transformações tecnológicas e a acirrada concorrência pela qualidade versus o baixo preço de produtos e serviços são desafios cada vez mais presentes no dia-a-dia 
dos líderes empresariais.

Questões como diferenciação e otimização de custos e processos operacionais que visam a excelência no desenvolvimento de trabalhos que não constituem a atividade-fim do negócio têm sido foco de grande atenção nas empresas. É nesse contexto que se insere a atual busca das corporações por soluções que representem uma nova forma de organizar seus processos, tendo sempre em vista a meta de assegurar eficiência e ganhos de escala.

Entre as soluções que hoje caminham para se consolidar entre os modernos modelos de gestão, a partir da realidade de empresas do Brasil e do mundo, estão os chamados Centros de Serviços Compartilhados - CSCs.

Entendidos como um modelo de organização de processos operacionais pelo qual uma área da empresa presta serviços, a partir de um mesmo ponto de atendimento, para várias unidades ou departamentos da corporação, os CSCs vêm ganhando espaço nas grandes e médias empresas como um meio de otimizar recursos e integrar tecnologias, processos e pessoas e, sobretudo, como um mecanismo essencial na geração de valor aos acionistas.

Em um estudo internacional realizado pela firma de consultoria Deloitte, denominado "O Futuro dos Serviços Compartilhados", em 2004, foram retratados os principais desafios e as perspectivas da adoção dessa prática a partir das respostas de grandes empresas dos mais diversos segmentos de atuação. Na época, foram apontadas como principais usuários do compartilhamento de serviços as áreas financeira, de recursos humanos, de cadeia de suprimentos, de funções administrativas e de tecnologia.

Mesmo com problemas que poderiam pesar negativamente na decisão das organizações em implementar CSCs regionais no Brasil, como a alta carga tributária, o país concentra considerável número de unidades de compartilhamento das empresas. O estudo apontou os processos relacionados à administração financeira - como contabilidade, contas a pagar e a receber, escrituração fiscal, folha de pagamento e tesouraria - como predominantes na utilização do CSC. Outras áreas que também estão no rol de atendimento são as de TI, help desk e suprimentos. Em média, os CSCs têm atendido a cerca de dez processos.

Nas últimas décadas, a Eletrobras vem se adaptando ao novo modelo do setor elétrico e as demandas de mercado, sendo assim, a Diretoria Executiva colocou em prática um realinhamento estratégico voltado à eficiência operacional, expansão sustentável e novo modelo de governança e gestão, desenvolvendo os Planos de Negócios e Gestão (PNGs).

Em 2017, foi lançado o PDNG-2017-2021 ("Desafio 21"-Excelência Sustentável) ratificando a necessidade de redução de custos em toda a companhia baseado em três pilares de eficiência: (i) Excelência Operacional; (ii) Disciplina Financeira e (iii) Governança e Conformidade [1].

Para o reforço do pilar de (i), foi desenvolvido um projeto de implantação de um CSC abrangendo oito processos: Recursos Humanos, Tecnologia da Informação, Contabilidade, Finanças, Jurídico, Serviços Gerais, Suprimentos e Logística.

\subsection{Lógica NEBUlosa}

A Lógica Nebulosa ou Lógica Fuzzy ou matemática nebulosa foi criada em 1965 a partir da publicação do artigo intitulado "Fuzzy Sets" por Lofti A. Zadhe, eletrônico e professor da Universidade da Califórnia, Berkeley [5, 6].

Ao contrário da lógica proposta por Aristóteles, filósofo grego (384 - 322 a.C.), que define uma regra rígida, atribuindo às afirmações valores "verdadeiro" ou "falso", a lógica nebulosa é baseada no uso de aproximações e consegue traduzir expressões verbais, imprecisas e vagas, comuns na comunicação humana, em valores numéricos [10].

A lógica nebulosa apresenta o princípio da dualidade, estabelecendo que dois eventos 
opostos podem coexistir, ou seja, um elemento pode pertencer, em certo grau, a um conjunto e, em outro grau, a um outro conjunto. Podemos identificar a aplicação desse conceito no nosso dia-a-dia, principalmente quando se trata de conceitos abstratos. Por exemplo, achar que uma pessoa é alta ou baixa.

Sendo assim, as varáveis podem assumir valores fuzzyficados, isto é, um grau de verdade não precisar assumir totalmente a verdade absoluta nem a falsidade absoluta, ou numericamente falando: zero ou um [5].

O objetivo de utilizar conjuntos fuzzy vem da necessidade de trabalhar com conjuntos do mundo real que não possuem limites precisos. Um conjunto fuzzy é um agrupamento impreciso ou indefinido, ou seja, um elemento pode ser membro de um conjunto de forma parcial, representado por um valor fracionário dentro de um intervalo numérico [10].

\section{METODOLOGIA}

A pesquisa se apresenta de natureza quantitativa, pois se baseia em números, cálculos matemáticos e números nebulosos para provar o experimento.

Para assa validação foi utilizado o software MATLAB ${ }^{1}$ (MATrix LABoratory), um sistema interativo de alta performance voltado para o cálculo numérico. O MATLAB integra análise numérica, cálculo com matrizes, processamento de sinais e construção de gráficos, entre outros.

O MATLAB, no seu ambiente de computação científica, conta com um recurso chamado Fuzzy Logical Toolbox, que estão disponibilizados arquivos e funções destinados ao uso da teoria de conjuntos fuzzy. Foi utilizado o FLD - Fuzzy Logic Designer existente na versão 2018b do MATLAB, conforme tela representada na figura 1.

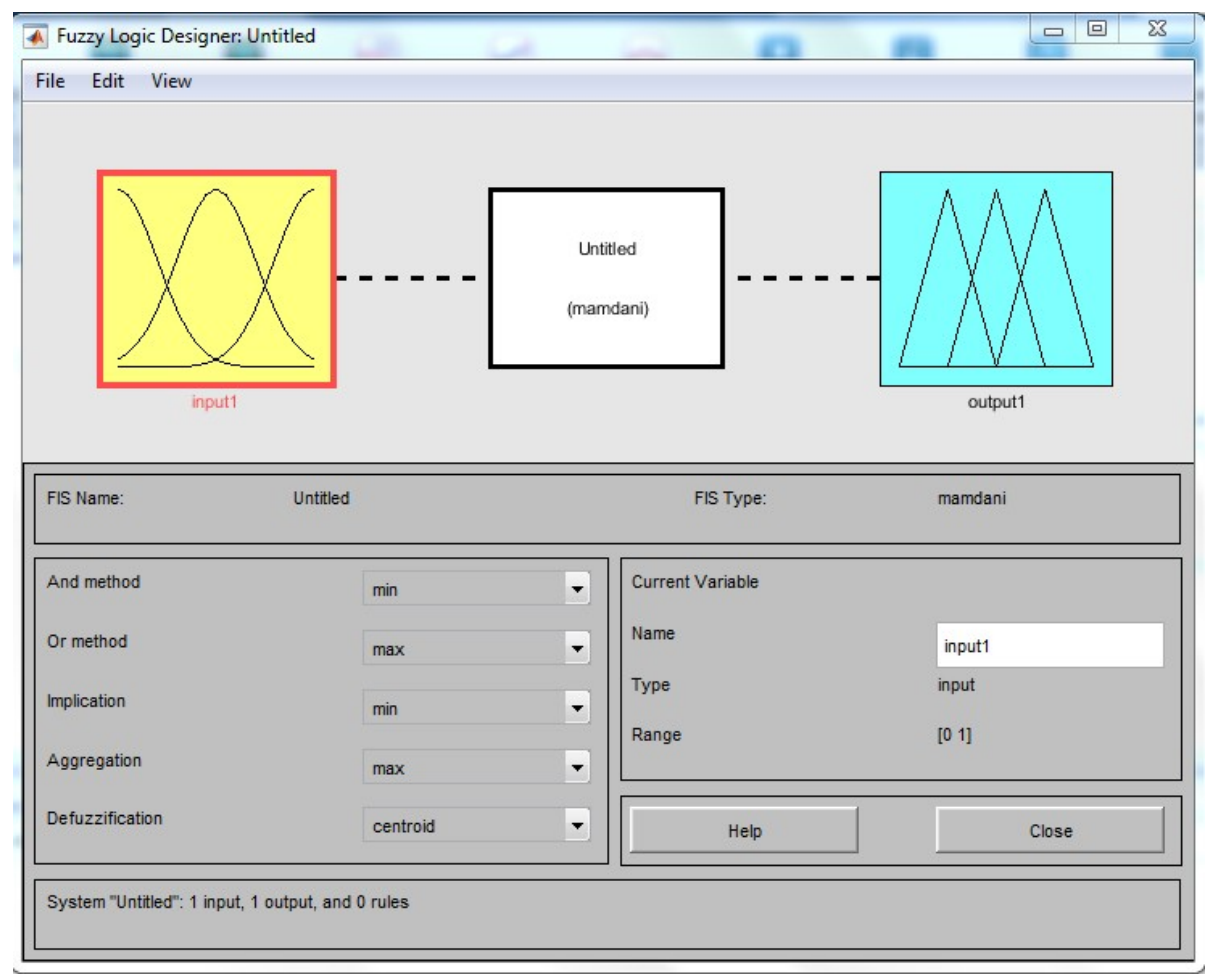

Figura 1: Tela do sistema Fuzzy no Matlab.

\footnotetext{
${ }^{1}$ https://www.mathworks.com/products/matlab.html 
Por fim, para validar a pesquisa foram comparados os resultados obtidos pela análise simples dos critérios com números nítidos estabelecidos (não fuzzy) contra o resultado fuzzy, além de ter sido validado com o especialista responsável pela área de aplicação.

\section{ESTUDO DE CASO}

Na maioria das empresas Eletrobras, a Logística de Material está fortemente vinculada às atividades de manutenção do sistema elétrico e à gestão de ativos, apoiando as equipes de manutenção e assegurando o atendimento dos planos de manutenção preventiva nas paradas de máquinas das usinas e manutenções programadas. Além de atuar no atendimento de emergências em linhas de transmissão, como nas quedas de torres e em subestações, visando minimizar os impactos na aplicação de multas e sanções, como a cobrança de parcela variável.

A Coordenação de Logística do CSC Eletrobras é responsável pela gestão de almoxarifados distribuídos em praticamente todo o território brasileiro. A Coordenação também é responsável pela definição de padrões de execução dos processos e o monitoramento do desempenho dos processos e atendimento dos níveis de serviço, a fim de garantir o cumprimento dos padrões de execução e de resultados acordados.

Além disto, a Coordenação de Logística busca assegurar uma melhor aderência dos processos ao recém-implantado sistema ERP Instância Única, o melhor controle do orçamento da conta de estoque, bem como a consolidação da gestão dos almoxarifados das empresas Eletrobras através de obras e reformas de adequação das instalações, tendo como principais diretrizes:

- Planejar e providenciar a disponibilidade de material, em tempo, custo e condições técnicas adequadas à manutenção da confiabilidade do sistema elétrico, dentro de padrões requeridos pela Companhia, e à continuidade de suas atividades operacionais e administrativas.

- Otimizar o estoque através do seu controle, saneamento permanente e da padronização do cadastro de material, atendendo à legislação pertinente, requisitos técnicos e atos normativos específicos.

- Realizar o desfazimento de material atendendo à legislação pertinente, requisitos técnicos e compromissos de responsabilidade socioambiental assumidos.

Em razão da ausência de uma visão centralizada, na origem da formação da estrutura de almoxarifados das empresas Eletrobras, e no planejamento da logística de material de estoque, verifica-se grande diversidade em termos de estruturas físicas, quantidade de itens armazenados e quadro de pessoal.

Desta forma, a integração dos processos através da implantação do ERP IU (Instância Única) e a reestruturação organizacional voltada à gestão por macroprocesso do seu CSC serviram de base para que a Coordenação de Logística iniciasse os estudos para a readequação da logística de material sobressalentes das empresas Eletrobras.

O estudo da readequação da rede almoxarifados das empresas Eletrobras tem como principais objetivos:

1. Aumentar a confiabilidade da logística;

2. Reduzir o valor do estoque;

3. Elevar o nível de serviço;

4. Sanear o estoque;

5. Reduzir o risco da falta; 
6. Reduzir o custo de armazenamento;

7. Reduzir o custo de transporte;

8. Adequar o quadro qualiquantitativo.

Para isto, o estudo propõe o estabelecimento de critérios técnicos para a revisão da estrutura de almoxarifados a partir da distribuição adequado do quadro de pessoal e a indicação de postos de autoatendimento, ou seja, pequenos almoxarifados administrados remotamente.

O estudo considerou as seguintes características dos almoxarifados:

- Quadro de pessoal

- Quantidade de itens armazenados

- Valor do estoque

- Movimentação de entradas e saídas de material do estoque

- Dimensão dos almoxarifados $\left(\mathrm{m}^{2}\right)$

A partir da análise comparativa entre as diferentes características dos almoxarifados das empresas, partiu-se para a elaboração da tabela de critérios para o estabelecimento do quadro de pessoal de referência apresentada na Figura 2, a qual foi baseada na avaliação de um especialista.

\begin{tabular}{|c|c|c|c|c|}
\hline Quadro Indicado & $\begin{array}{l}\text { Quantidade de } \\
\text { Itens em estoque }\end{array}$ & Valor do estoque & $\begin{array}{c}\text { Quantidade de } \\
\text { movimentações } \\
\text { anuais }\end{array}$ & $\begin{array}{c}\text { Área do } \\
\text { almoxarifado }(\mathrm{m} 2)\end{array}$ \\
\hline$\overline{\text { PAA }}$ & até 1.500 & até R\$1 milhão & até 1.000 & até 600 \\
\hline 1 ALMOXARIFE & de 1.500 até 3.500 & de $\mathrm{R} \$ 1$ milhão até $\mathrm{R} \$ 3$ milhões & de 1.000 até 3.500 & de 600 até 2.000 \\
\hline 2 ALMOXARIFES & de 3.500 até 5.800 & de $\mathrm{R} \$ 3$ milhão até $\mathrm{R} \$ 7$ milhões & de 3.500 até 5.000 & de 2.000 até 3.000 \\
\hline 3 ALMOXARIFES & acima de 5.800 & acima de R\$7 milhões & acima de 5.000 & acima de 3.000 \\
\hline
\end{tabular}

Figura 2: tabela de critérios para o estabelecimento do quadro de pessoal de referência.

Para validação e confirmação dos critérios propostos foi utilizado o método de inferência fuzzy. Para cada variável apresentada na figura foi criado um número nebuloso, procurando seguir os intervalos correspondentes com grau de pertinência em 100\% para um intervalo de valores médios da tabela apresentada com valores nítidos e utilizando uma escala com quatro graus de resposta: Baixo, Médio, Alto e Muito Alto.

As varáveis de entrada mapeadas foram:

- Itens em Estoque;

- Valor em Estoque;

- Movimentação;

- Área $\left(\mathrm{m}^{2}\right)$;

A varável de saída mapeada corresponde à indicação do tipo do Almoxarifado indicado para cada situação analisada e foi denominada:

- Classificação do Almoxarifado;

Tomando como exemplo a vaiável "Itens de Itens”, o grau "Baixo” equivaleria até 1.500 itens; "Médio", entre 1.500 e 3.500; “Alto", entre 3.500 e 5.800 e "Muito alto" acima de 5.800 itens em estoque, conforme figura 3. 
Neste estudo, foi utilizada a função de pertinência do tipo Trapezoidal, uma vez que é possível manter um grau de pertinência máximo por um intervalo de valores, pois é uma das características apresentada pelo especialista para as variáveis do estudo.

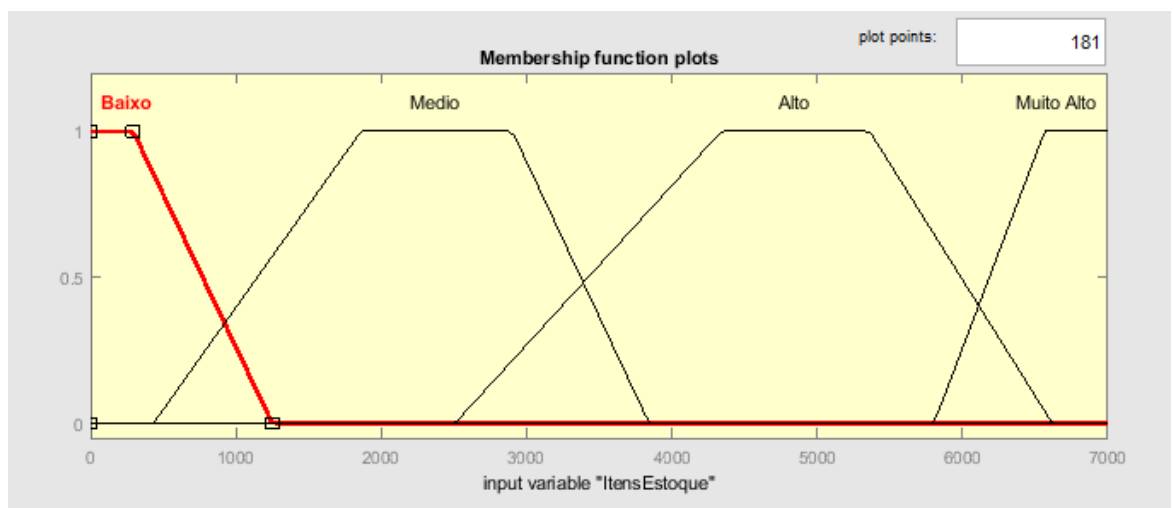

Figura 3: Funções de pertinência para a variável "Itens Estoque"

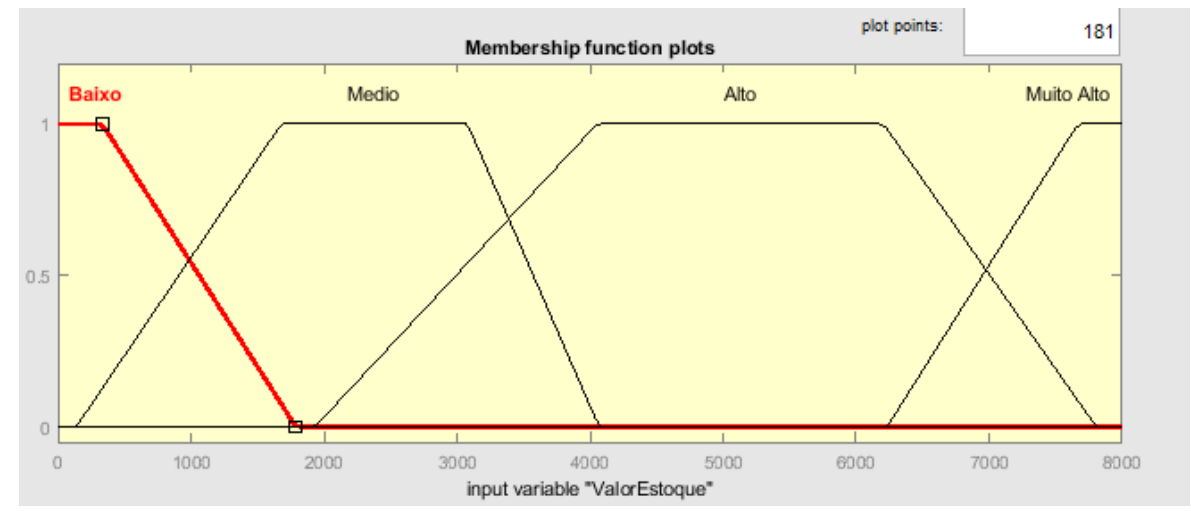

Figura 4: Funções de pertinência para a variável "Valor Estoque”

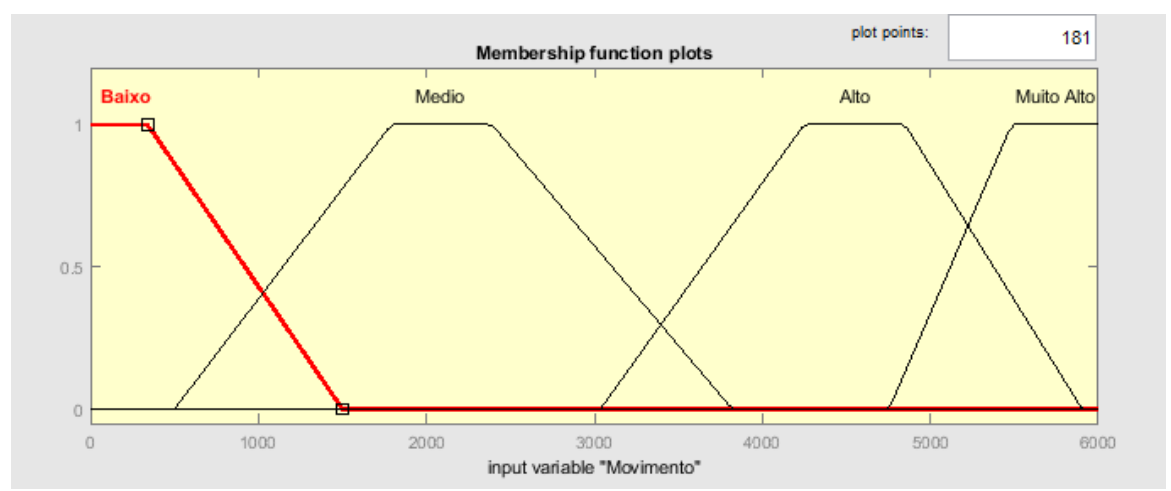

Figura 5: Funções de pertinência para a variável "Movimento" 


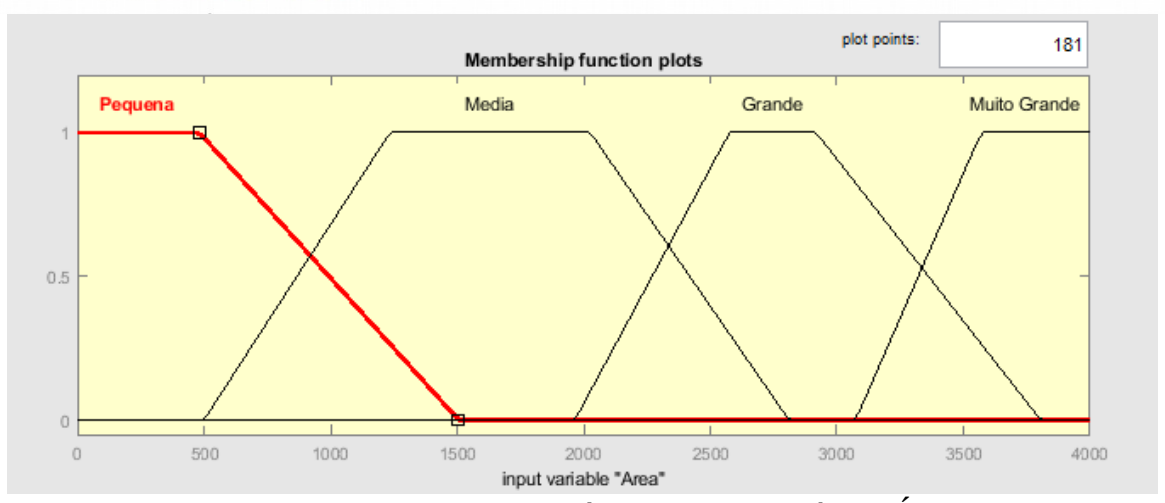

Figura 6: Funções de pertinência para a variável “Área”

Como resultado da inferência fuzzy, a variável de saída foi denominada “Classificação do Almoxarifado”, com os seguintes resultados:

- PAA

- Tipo 01

- Tipo 02

- Tipo 03

O PAA corresponde a um posto de atendimento não assistido, ou seja, onde não há funcionário operando e não chega a ter status de almoxarifado. O almoxarifado tipo 01, recomenda-se que tenha pelo menos um almoxarife trabalhando, ou uma força de trabalho em tempo integral ou um FTE, do inglês “full-time equivalent”. Os demais tipos 2 e 3 denotam 2 e 3 FTEs, respectivamente.

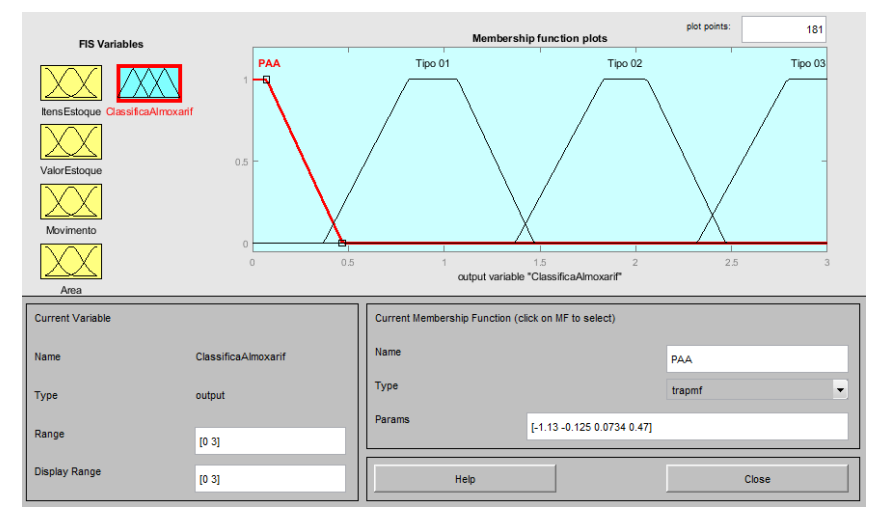

Figura 7: Funções de pertinência para a variável “Classificação do Almoxarifado”

O sistema de inferência fuzzy foi construído com quatro variáveis de entrada (input) e uma de saída (output), nesse sentido foram construídas 42 regras de inferência. A Figura 8 apresenta as 20 primeiras regras construídas a partir da visão do especialista. 


\begin{tabular}{|c|c|c|c|c|c|c|}
\hline$\#$ & Itens estoque & Valor estoque & Movimentacao & Área & $-->$ & Class. Almoxarifado \\
\hline 1 & Baixo & Baixo & Baixa & Pequena & & PAA \\
\hline 2 & Baixo & Médio & Baixa & Pequena & & PAA \\
\hline 3 & Baixo & Baixo & Médio & Pequena & & TIPO 1 \\
\hline 4 & Baixo & Baixo & Baixa & Média & & PAA \\
\hline 5 & Médio & Baixo & Baixa & Pequena & & PAA \\
\hline 6 & Médio & Médio & Baixa & Pequena & & PAA \\
\hline 7 & Médio & Alto & Baixa & Pequena & & PAA \\
\hline 8 & Médio & Médio & Médio & Média & & TIPO 1 \\
\hline 9 & Baixo & Médio & Médio & Média & & TIPO 1 \\
\hline 10 & Médio & Baixo & Médio & Média & & TIPO 1 \\
\hline 11 & Médio & Médio & Baixo & Média & & TIPO 1 \\
\hline 12 & Médio & Médio & Médio & Grande & & TIPO 1 \\
\hline 13 & Alto & Médio & Médio & Média & & TIPO 1 \\
\hline 14 & Médio & Alto & Médio & Média & & TIPO 1 \\
\hline 15 & Médio & Médio & Alto & Média & & TIPO 2 \\
\hline 16 & Médio & Médio & Médio & Grande & & TIPO 1 \\
\hline 17 & Baixo & Baixo & Alto & Pequena & & TIPO 1 \\
\hline 18 & Alto & Alto & Médio & Grande & & TIPO 1 \\
\hline 19 & Muito Alto & Médio & Médio & Média & & TIPO 1 \\
\hline 20 & Médio & Muito Alto & Médio & Média & & TIPO 1 \\
\hline
\end{tabular}

Figura 8: Base de regras de inferência fuzzy

Depois disso, as regras foram cadastradas no Matlab, no módulo de regras fuzzy e a figura 9 apresenta parte da base de regras editada no toolbox fuzzy, módulo Rules View.

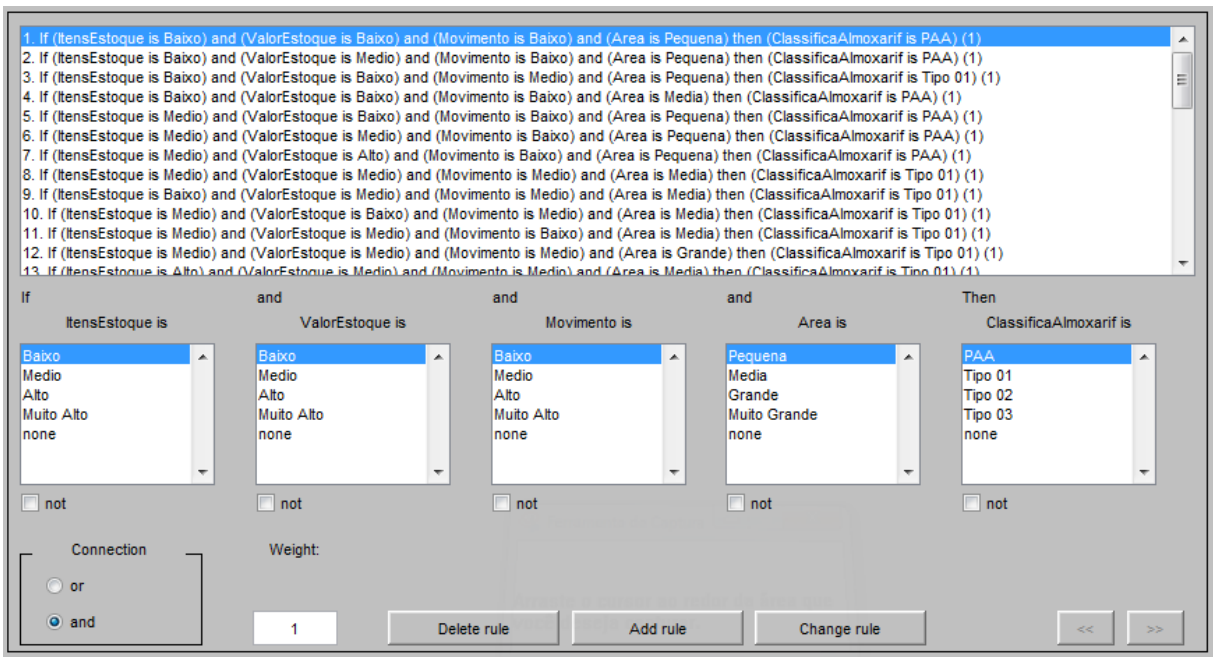

Figura 9: Regras fuzzy criadas no Matlab toolkit

Outra forma de apresentar as regras é através do visualizador de regras fuzzy do Matlab, demonstrado na figura 10, em que podemos alterar em tempo real os valores das variáveis de entrada e o resultado fuzzy é calculado automaticamente. 


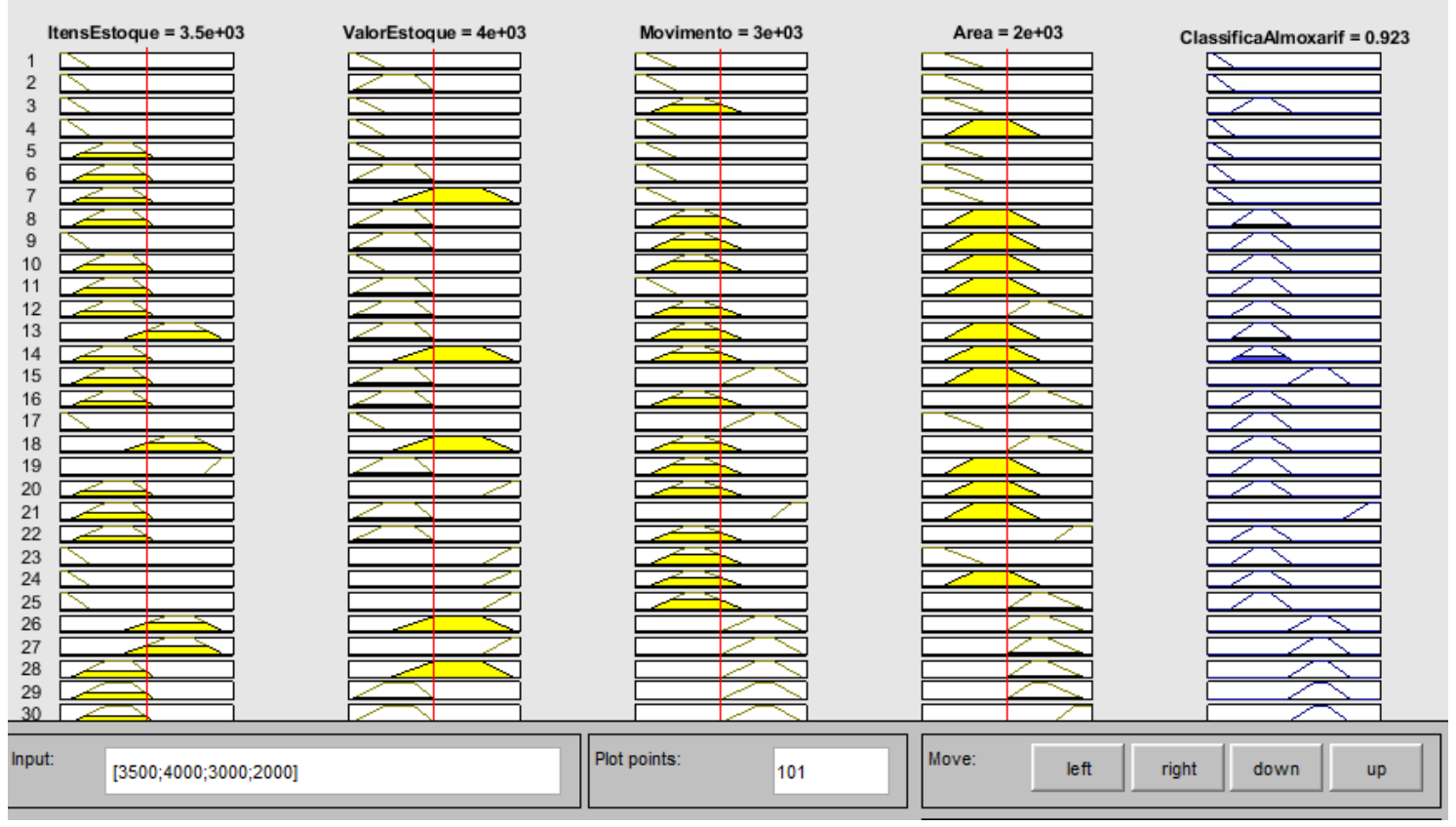

Figura 10: Funções de pertinência para a variável "Itens Estoque”

Outra abordagem muito interessante para visualizar como o sistema de inferência fuzzy funciona é através do gráfico de superfície. Esse gráfico permite combinar até três variáveis ao mesmo tempo e apresenta o resultado em forma 3D. Esses gráficos podem explicar, de maneira mais simples, objetiva e atrativa ao público em geral, os resultados encontrados nas matrizes de interação. Por exemplo, a figura 11 apresenta dois gráficos, o primeiro levando em conta a análise movimento vs. itens de estoque e o segundo gráfico considerando movimento vs. valor de estoque. Ambos apresentam no eixo y (altura) a classificação do almoxarifado.
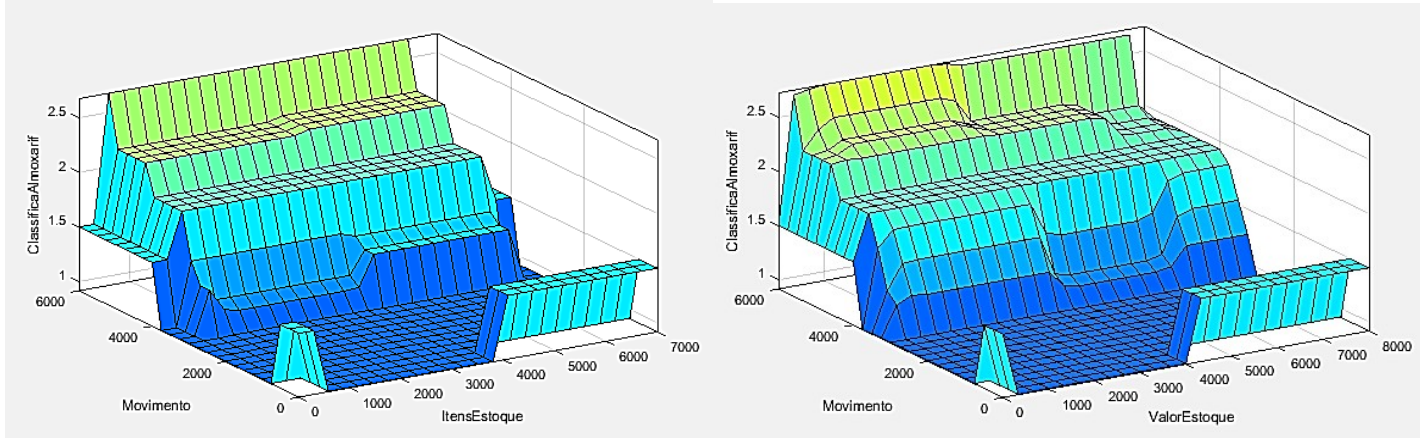

Figura 11: Gráficos de Superfície 3D combinando três variáveis

Outra visualização que pode ser útil na análise dos resultados das regras criadas é o mapa de calor, que combina duas variáveis, desta vez em um plano 2D, porém com cores que variam do vermelho ao amarelo, conforme apresentado na figura 12. 

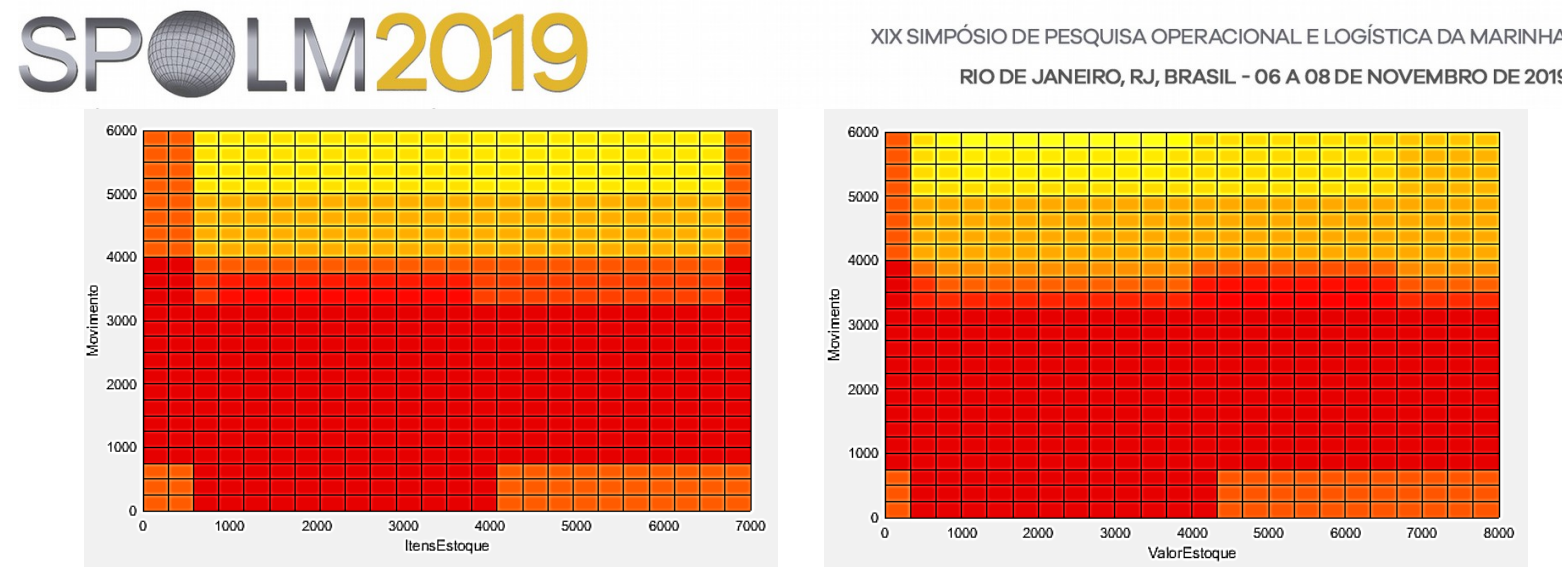

Figura 12: Mapa de Calor 2D combinando duas variáveis

Após a criação do sistema de inferência Fuzzy, foi feita uma compilação de dados de 68 almoxarifados espalhados pelo Brasil, conforme figura 13. Os nomes dos almoxarifados foram suprimidos e foram criados códigos para identificá-los.

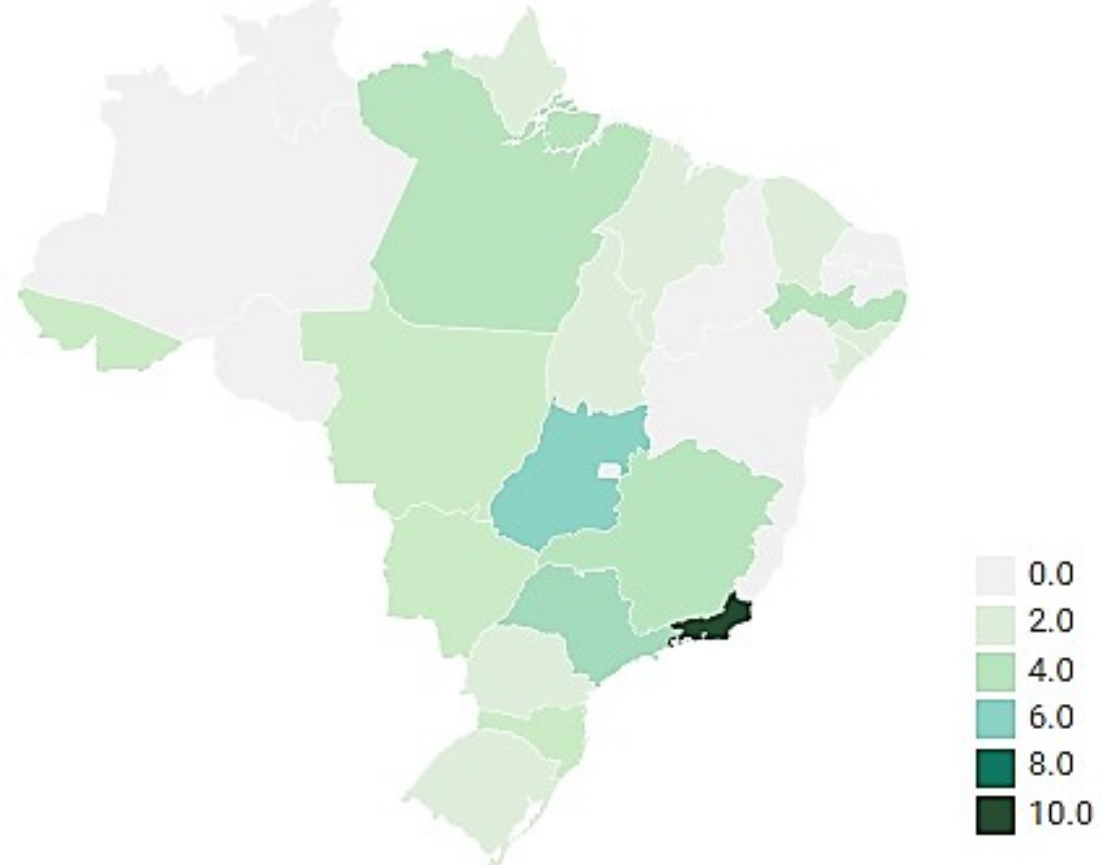

Figura 13: Almoxarifados espalhados pelos Estados Brasileiros

Além dos quatro dados de entrada fuzzy (Itens em Estoque; Valor em Estoque; Movimentação; Área), a localização, UF, também foram levantados os dados da força de trabalho atual, o que totalizou 98 FTEs para atender os 68 almoxarifados.

\section{ANÁLISE DOS RESULTADOS}

Antes da execução do sistema de inferência fuzzy, o especialista, que acompanhou a pesquisa, realizou a tarefa de classificação dos 68 almoxarifados utilizando as regras definidas na figura 2, de forma cartesiana.

O especialista fez sua avaliação de forma manual, analisando cada almoxarifado individualmente, através da observação simples das regras estabelecidas, conforme consta na figura 2. A principal dificuldade relatada pelo especialista foi a de encontrar vários casos em que um almoxarifado apresentava características distintas em duas variáveis ou mais, o que dificultava a tomada de decisão. Por exemplo, havia um almoxarifado com até 1500 itens, 
porém, com valor do estoque acima de R\$ 2 milhões e ainda com quantidade de movimentação alta, acima dos 3.500. Nesse caso, havia características que apontava para um PAA, 1 e 2 almoxarife ao mesmo tempo. Nesses casos, a tomada de decisão era empírica. Essa análise do especialista durou três dias.

O resultado da análise do especialista foi que para os 68 almoxarifados estudados, chegou-se a um montante de 57 FTEs necessários, ao invés dos 98 atuais, o que representa uma redução de 41 FTEs face ao quadro atual.

Após isso, foi feita a execução do sistema de inferência fuzzy no Matlab para os mesmo 68 almoxarifados. O resultado do modelo fuzzy apresentou um total de 53 FTEs para administrar os mesmos 68 almoxarifados, uma redução de 44 FTEs com relação ao quadro atual e uma redução de 4 FTEs sobre o estudo feito pelo especialista utilizando o método cartesiano com as regras estabelecidas. Essa execução durou aproximadamente 3 minutos em um computador desktop simples (Intel Core 2 Duo, $3.00 \mathrm{GHz}, 8 \mathrm{~GB}$ ). O resultado pode ser observado na figura 14.

\begin{tabular}{|c|c|c|c|c|c|c|c|}
\hline ref. & Atual & Proposto & fuzzy & ref. & Atual & Proposto & fuzzy \\
\hline $\mathrm{ABA} 01$ & 0 & 0 & 1 & AAR35 & 0 & 0 & 0 \\
\hline ASE02 & 2 & 1 & 1 & AAU 36 & 0 & 0 & 0 \\
\hline AGU03 & 0 & 0 & 0 & AAL37 & 5 & 3 & 3 \\
\hline AMA0 4 & 1 & 1 & 1 & AAL38 & 6 & 2 & 2 \\
\hline ARI05 & 0 & 0 & 0 & APA39 & 0 & 0 & 0 \\
\hline $\mathrm{ACO06}$ & 1 & 1 & 0 & APA40 & 0 & 0 & 0 \\
\hline AIT07 & 3 & 2 & 2 & APA41 & 0 & 0 & 0 \\
\hline $\mathrm{ABA0} 0$ & 0 & 0 & 0 & APA42 & 0 & 0 & 0 \\
\hline AIB09 & 2 & 2 & 2 & APA43 & 0 & 0 & 0 \\
\hline AIT10 & 0 & 0 & 1 & APA 44 & 0 & 0 & 0 \\
\hline ATI11 & 3 & 1 & 1 & APA45 & 0 & 0 & 0 \\
\hline $\mathrm{AFO} 12$ & 2 & 2 & 2 & APM4 6 & 0 & 1 & 2 \\
\hline AIV13 & 0 & 1 & 1 & APA47 & 0 & 0 & 0 \\
\hline APO14 & 0 & 0 & 1 & APA48 & 0 & 0 & 0 \\
\hline AMA15 & 1 & 1 & 1 & APA49 & 0 & 0 & 0 \\
\hline ALU16 & 2 & 1 & 1 & APA50 & 0 & 0 & 0 \\
\hline APO17 & 2 & 1 & 1 & APM51 & 0 & 1 & 1 \\
\hline AMA18 & 2 & 2 & 2 & ASE 52 & 8 & 2 & 1 \\
\hline AFU19 & 2 & 1 & 1 & AAL53 & 6 & 1 & 1 \\
\hline ACA20 & 1 & 0 & 0 & AAL54 & 0 & 1 & 1 \\
\hline AJA21 & 4 & 2 & 2 & AAL55 & 3 & 2 & 1 \\
\hline AAN22 & 0 & 0 & 1 & AAL56 & 1 & 1 & 1 \\
\hline ACA23 & 2 & 2 & 2 & AAL57 & 3 & 1 & 1 \\
\hline AVI24 & 4 & 2 & 1 & AAL58 & 2 & 1 & 1 \\
\hline ASE25 & 3 & 2 & 1 & AAL59 & 3 & 1 & 1 \\
\hline AAL26 & 3 & 2 & 0 & AAL 60 & 2 & 1 & 1 \\
\hline AAL27 & 3 & 1 & 1 & AAL 61 & 3 & 0 & 1 \\
\hline AAF28 & 3 & 3 & 2 & AAL 62 & 2 & 1 & 0 \\
\hline AAC29 & 0 & 0 & 1 & AAL 63 & 0 & 0 & 0 \\
\hline AAB30 & 2 & 1 & 1 & AAL 64 & 0 & 1 & 1 \\
\hline AAU31 & 0 & 0 & 0 & AAL 65 & 3 & 1 & 1 \\
\hline AAU32 & 0 & 0 & 0 & AAL 66 & 0 & 0 & 0 \\
\hline AAL33 & 0 & 0 & 0 & AAL 67 & 2 & 2 & 1 \\
\hline \multirow[t]{2}{*}{ AAR34 } & 1 & 2 & 1 & AAL 68 & 0 & 0 & 0 \\
\hline & & & & Total & 98 & 57 & 53 \\
\hline
\end{tabular}

Figura 14: Análise de FTEs pelos Almoxarifados (atual, proposto e fuzzy)

Importante destacar que o modelo fuzzy não reduziu simplesmente 4 FTEs no global, mas, para chegar nesse resultado, o modelo fuzzy convergiu com a opinião cartesiana do especialista em 51 casos, porém fez otimizações em análises em 17 almoxarifados, trazendo à tona posições divergentes tendo como base o modelo cartesiano e se mostrando uma opção de ferramenta para apoio a tomada de decisão sobre o número de FTEs final para os almoxarifados. Conforme demonstrado na figura 15. 


\begin{tabular}{|l|rrr|}
\hline \multicolumn{1}{|c|}{ ref. } & Atual & Proposto & fuzzy \\
\hline ABA01 & 0 & 0 & 1 \\
ACO06 & 1 & 1 & 0 \\
AIT10 & 0 & 0 & 1 \\
APO14 & 0 & 0 & 1 \\
AAN22 & 0 & 0 & 1 \\
AVI24 & 4 & 2 & 1 \\
ASE25 & 3 & 2 & 1 \\
AAL26 & 3 & 2 & 0 \\
AAF28 & 3 & 3 & 2 \\
AAC29 & 0 & 0 & 1 \\
AAR34 & 1 & 2 & 1 \\
APM46 & 0 & 1 & 2 \\
ASE52 & 8 & 2 & 1 \\
AAL55 & 3 & 2 & 1 \\
AAL61 & 3 & 0 & 1 \\
AAL62 & 2 & 1 & 0 \\
AAL67 & 2 & 2 & 1 \\
Total & $\mathbf{3 3}$ & $\mathbf{2 0}$ & $\mathbf{1 6}$ \\
\hline
\end{tabular}

Figura 15: Análise dos FTEs divergentes entre os 17 almoxarifados

Por meio da figura 16, pode-se perceber que o modelo fuzzy, em alguns casos recomenda a existência de um almoxarife em determinado almoxarifado, é o caso do ABA01, onde a análise do especialista apontou, inicialmente, um PAA, ou seja, um posto desassistido, sem almoxarife. Por outro lado, no caso ACO06, o modelo fuzzy apontou para um posto desassistido, enquanto o especialista havia apontado a necessidade de 1 FTE.

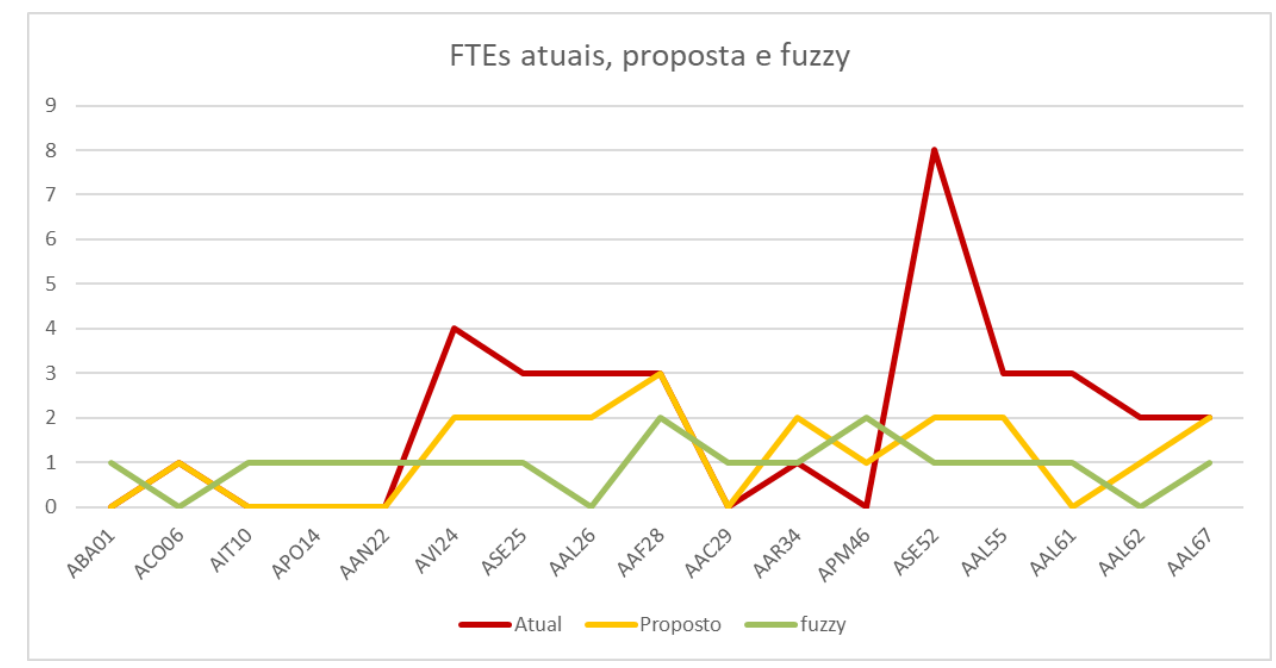

Figura 16: Análise gráfica dos FTEs divergentes entre os 17 almoxarifados

\section{CONSIDERAÇÕES FINAIS}

O presente artigo teve como objetivo apresentar o estudo para a definição de critérios para a readequação da estrutura de logística de material das empresas Eletrobras, a partir de ferramentas de sistema de inferência fuzzy, ou lógica nebulosa, considerando as especificidades dos almoxarifados.

Foram mapeadas quatro variáveis de entradas (itens em estoque, valor em estoque, 
movimentação, área) e uma de saída (classificação do almoxarifado), além de 42 regras de inferência nebulosa. O software matemático Matlab foi utilizado para executar o método de inferência fuzzy.

O especialista em logística apoiou a pesquisa e fez a avaliação da classificação de 68 almoxarifados, através do modelo cartesiano estabelecido. Por conta disso, foram identificados a necessidade de 57 FTEs.

Por outro lado, o modelo de inferência fuzzy foi aplicado e chegou ao resultado mais otimizado com 53 FTEs no total contra 57 da visão do especialista. Porém, o ponto relevante da pesquisa foi que essa redução não foi meramente quantitativa, mas também qualitativa, uma vez que envolveu a otimização da análise de 17 almoxarifados.

Sendo assim, a pesquisa se justificou, uma vez que o modelo apresentado se apresentou como um instrumento válido e importante de apoio à tomada de decisão para reenquadramento logístico do CSC da Eletrobras.

\section{REFERÊNCIAS BIBLIOGRÁFICAS}

[1] ELETROBRAS. Sobre a Eletrobras, disponível em: www.eletrobras.com. Acesso em: 23 mar. 2019.

[2] NOVAES, A.G. Logística e Gerenciamento da Cadeia de Distribuição. $3^{\text {a }}$ Edição. Campus. Rio de Janeiro, RJ, 2001.

[3] BALLOU, Ronald H. Logística Empresarial: Transportes, administração de materiais e distribuição física. São Paulo: Atlas, 2011.

[4] BARROS, Nivia Valença. Curso: Capacitação para Conselhos Tutelares - Projeto SIPIA ministrado na Faculdade de Administração - Niterói /UFF, 14, 15 e 17 de julho de 2005.

[5] BRAGA, Mario J. F.; BARRETO, Jorge M.; MACHADO, Maria Augusta S. Conceitos da Matemática Nebulosa na Análise de Risco. Rio de Janeiro: Artes\& Rabiskus, 1995.

[6] COSTA, Alex da; RODRÍGUEZ, Antonio Gabriel; SIMAS, Etiene P. L.; ARAÚJO, Roberto da S. Lógica Fuzzy: Conceitos e Aplicações. Disponível em: $<$ http://www.inf.unisinos.br/ cazella/dss/fuzzy_relatorio.pdf $>$. Acesso em: 04 nov. 2018.

[7] GOMES, Carla Amado; SAMPAIO, Jorge Silva. Biocombustíveis: a caminho de uma 'sociedade de reciclagem. In: e-Pública - Revista Eletrónica de Direito Público, v. 4, n. 3, pp. 390-418, nov. 2017.

[8] LAMBERT, Rosebud Jasmine; SILVA, Patrícia Pereira da. The challenges of determining the employment effects of renewable energy. In: Renewable \& Sustainable Energy Reviews, v. 16, issue 7, pp. 4667-4674, set. 2012.

[9] SILVA, Patrícia Pereira da. O Sector da Energia Eléctrica na União Europeia: Evolução e Perspectivas. Coimbra: Imprensa da Universidade de Coimbra, 2007.

[10] SIMÕES, Marcelo G.; SHAW, Lan. Controle e Modelagem Fuzzy. São Paulo: Edgard \& Blucher, 1999. 
[11] BOWERSOX, Donald J.; CLOSS, David J. Logística empresarial: o processo de integração de cadeia de suprimento. $1^{a}$ ed. São Paulo: Atlas, 2010.

[12] GONÇALVES, Paulo Sergio. Administração de materiais. $3^{\text {a }}$ ed. Rio de Janeiro: Elsevier, 2010 